\title{
Da exigência de comum acordo para a instauração dos dissídios coletivos frente ao princípio da inafastabilidade da jurisdição
}

\author{
Luciana de Miguel Cardoso ${ }^{1}$ \\ Prof. Dr. Lourival José de Oliveira ${ }^{2}$
}

\begin{abstract}
Resumo
Nas relações de trabalho, muitas vezes surgem conflitos que dizem respeito a uma categoria de trabalhadores e podem envolver uma empresa ou categoria econômica. Esses conflitos coletivos podem ser solucionados por autocomposição, que é a negociação coletiva, ou por heterocomposição, que pode ser por mediação, arbitragem ou via judicial. A negociação coletiva permite às próprias partes acordarem as condições ideais e possíveis para o momento. No entanto, quando as partes não conseguem chegar a um acordo, torna-se necessária a intervenção do Estado para a pacificação do conflito pela via judicial, por meio da instauração de um dissídio coletivo. A Emenda Constitucional no 45, de 8 de dezembro de 2004, trouxe inovações para a propositura dos dissídios coletivos de interesse, que são aqueles que versam sobre condições de trabalho. A nova redação do artigo 114, parágrafo segundo, da Constituição Federal estabeleceu que a propositura do dissídio, nesse caso, deve ser por "comum acordo". A inclusão da necessidade de comum acordo dificultou sobremaneira a propositura da ação, criando no ordenamento uma ação que depende da anuência da parte contrária para sua propositura. Por essa razão, entendeu-se que se está afastando um conflito da tutela jurisdicional. Admitir a necessidade de propositura em conjunto seria tirar do Estado um dever de pacificação social, deixando muitos conflitos sem solução. A única alternativa para os trabalhadores acabaria sendo o apelo à greve, para forçar a empresa ou a categoria econômica a negociar.
\end{abstract}

Palavras Chave: Dissídio coletivo; Conflito coletivo; Direito de ação.

\section{Introdução}

Após um longo período de debates, a Reforma do Judiciário consubstanciou-se na Emenda Constitucional no 45, aprovada em 8 de dezembro de 2004, que trouxe inúmeras alterações ao Poder Judiciário.

A Justiça do Trabalho sofreu grandes modificações, com ampliação de seu rol de competências e alterações de grande importância no âmbito dos dissídios coletivos. Novos

Aluna do curso de Especialização em Direito do Estado da Universidade Estadual de Londrina.

Orientador. Doutor em Direito do Trabalho; Professor adjunto da Universidade Estadual de Londrina; Professor Titular da Unopar; Professor do Curso de Mestrado em Direito Negocial da UEL; Professor do Programa de Mestrado da Unimar; Professor de Graduação da FACCAR. 
requisitos foram instituídos para os dissídios de interesses, gerando controvérsias sobre o futuro da função normativa da Justiça do Trabalho.

A complexidade da matéria atraiu grande manifestação da doutrina e toda contribuição parece ser relevante, para que se consiga chegar rapidamente a uma harmonia doutrinária e jurisprudencial, visando solucionar a questão para as maiores interessadas, que são as categorias envolvidas, trabalhadores e empresas.

O presente estudo possui como proposta estudar as inovações para a propositura das ações coletivas de dissídios de interesses, especialmente a exigência de "comum acordo" para seu ajuizamento, e discutir a necessidade de participação do Estado na solução dos conflitos coletivos do trabalho.

Discute-se qual a natureza jurídica do consentimento da parte contrária e se sua obrigatoriedade para a instauração do dissídio pode afastar o conflito da tutela jurisdicional, ferindo o direito subjetivo de agir garantido constitucionalmente.

\section{Conflitos coletivos do trabalho}

\subsection{Conceito de conflito coletivo do trabalho}

Assim como ocorre em qualquer área da vida em sociedade, também nas relações de trabalho surgem conflitos, como fenômeno inerente ao convívio em coletividade. Os conflitos trabalhistas, no entanto, apresentam certas particularidades em relação aos conflitos na área cível, em razão de as partes, empregado e empregador, encontrarem-se no mundo fático em situação de desigualdade. Daí a relevância que deve ser dada às formas de organizações de trabalhadores, como instrumentos que buscam a redução dessa desigualdade.

Os conflitos trabalhistas podem ser classificados em conflitos individuais e coletivos. Amauri Mascaro Nascimento (2002, p. 4) entende que são coletivos os conflitos que envolvem um grupo abstrato, "pessoas não determinadas unidas em torno de um ponto comum", e são individuais aqueles que envolvem "pessoas determinadas agindo no interesse próprio, direto e imediato".

Segundo Wagner D. Giglio (2002, p. 381), devem ser analisados três critérios para diferenciar os conflitos coletivos dos individuais: partes, objeto e finalidade. Nos conflitos 
coletivos, pelo menos uma das partes (trabalhadores) é uma coletividade, composta por número indeterminado de indivíduos, enquanto nos individuais sempre estão indivíduos determinados. Os objetos dos conflitos coletivos são interesses abstratos e o dos individuais são interesses concretos. O conflito coletivo tem como finalidade a criação, modificação ou interpretação de uma norma, ao passo que o conflito individual visa a aplicação de norma preexistente ao caso concreto.

Assim, os conflitos coletivos surgem quando um grupo de trabalhadores indeterminados defende interesses abstratos, pertencentes a toda categoria, com o fim de criar, modificar ou interpretar uma norma.

Os conflitos coletivos podem ser classificados em conflitos econômicos e jurídicos. Os conflitos econômicos, também chamados de conflitos de interesse, são aqueles em que os trabalhadores reivindicam novas condições de trabalho ou melhores salários. Os conflitos jurídicos, ou de direito, visam a "interpretação ou aplicação de determinada norma jurídica ao caso em exame" (MARTINS, 2005, p. 77).

A expressão "conflito econômico" é largamente usada pelos doutrinadores, mas Amauri Mascaro Nascimento $(1989$, p. 259) orienta que "pode prestar-se a equívocos, uma vez que dá a idéia de um bem econômico, quando não é essa a sua função no problema, mas a de indicar que o conflito é de natureza constitutiva de novo conteúdo normativo para as relações coletivas de trabalho mantidas entre os sujeitos conflitantes".

Fábio Túlio Correia Ribeiro (1997, p. 231) completa que basta que a pretensão "signifique a conquista de novos direitos para a classe trabalhadora, ou o incremento dos já reconhecidos, ainda que sem expressão em pecúnia".

Os conflitos coletivos econômicos são, dessa forma, as controvérsias que surgem entre um grupo de trabalhadores ou a categoria profissional e uma empresa ou a categoria econômica, em busca de novas condições de trabalho, com o fim de criar, modificar ou extinguir normas.

\subsection{Formas de solução dos conflitos coletivos do trabalho}

Em busca da harmonização das relações entre patrões e empregados, surgem vários meios de composição dos conflitos coletivos do trabalho. 
Amauri Mascaro Nascimento (2002, p. 5) destaca três formas de solução dos conflitos: autodefesa, autocomposição e heterocomposição.

A autodefesa manifesta-se quando há "solução direta entre os litigantes pela imposição de um sobre o outro" (NASCIMENTO, 2002, p. 5). É uma forma primitiva de solução de conflitos, pois uma parte impõe sua vontade sem o consentimento da outra. Os principais exemplos de autodefesa na esfera trabalhista são a greve e o lockout, sendo o lockout vedado pela legislação brasileira.

Na autocomposição, o conflito também é solucionado pelas próprias partes, mas há um ajuste de vontades (NASCIMENTO, 2002, p. 6), os opositores chegam a um entendimento. Quando apenas um consente no sacrifício do próprio interesse, há a renúncia, forma de autocomposição unilateral, e quando ambos consentem, há a transação, que é autocomposição bilateral.

Christóvão Piragibe Tostes Malta (2000, p. 21) considera a existência de três meios de autocomposição, que pode ocorrer pela desistência (renúncia à pretensão), pela submissão (renúncia à resistência oferecida à pretensão) ou pela transação (concessões recíprocas). A desistência e a submissão são, em verdade, formas de renúncia, de autocomposição unilateral.

A terceira forma de solução de conflitos - heterocomposição - é uma solução por uma "fonte suprapartes, que decide com força obrigatória sobre os litigantes" (NASCIMENTO, 2002, p. 6).

Alguns doutrinadores, no entanto, não incluem a autodefesa como forma de solução dos conflitos.

Amador Paes de Almeida (1998, p. 341) considera haver três espécies de solução dos conflitos coletivos do trabalho: livre negociação, arbitragem e jurisdição. A livre negociação é a autocomposição e a arbitragem e a jurisdição são formas de heterocomposição.

Christóvão Piragibe Tostes Malta (2000, p. 21) explica que também rejeita a autodefesa e entende que ou há autocomposição ou as partes buscam a heterocomposição.

A autocomposição ou livre negociação é aquela estabelecida pelas próprias partes interessadas e é conhecida como negociação coletiva. 
A negociação coletiva é considerada a melhor forma de solução de conflitos pela Organização Internacional do Trabalho (GIGLIO, 2002, p. 382), pois somente as próprias partes sabem exatamente os limites de negociação. A regulamentação ocorre pelo consenso e, assim, a negociação admite maior flexibilidade e possibilidade de adaptação a circunstâncias e conjunturas.

Russomano (2006) explica que a negociação coletiva é a "função primordial do sindicato na sociedade moderna, [...] constitui o instrumento doutrinariamente preferencial no processo de flexibilização do Direito do Trabalho".

Por essa razão, a legislação trabalhista brasileira vem acolhendo cada vez mais a autocomposição, reconhecendo os acordos e as convenções coletivas de trabalho como formas de negociação coletiva.

Wagner D. Giglio (2002, p. 383) explica, contudo, que a implantação do sistema de autocomposição dos conflitos pressupõe requisitos inexistentes entre nós, especialmente a autenticidade da vida sindical. Nas palavras do autor, "a liberdade para negociar exige posição de igualdade entre os contendores, somente alcançada por sindicatos fortes, independentes, com poder de arregimentação da categoria".

Assim, quando as partes não conseguem a autocomposição, podem buscar uma solução por intermédio de um terceiro, que está fora do conflito.

Amauri Mascaro Nascimento (2002, p. 13) e Sérgio Pinto Martins (2005, p. 79) consideram haver três técnicas heterocompositivas: mediação, arbitragem e jurisdição.

A mediação é "técnica de composição dos conflitos caracterizada pela participação de um terceiro suprapartes, o mediador, cuja função é ouvir as partes e formular propostas" (NASCIMENTO, 2002, p. 13). As partes, no entanto, não são obrigadas a aceitar as propostas, o mediador apenas interfere para aproximar as vontades divergentes dos litigantes, o que gera alguma divergência na doutrina quanto à natureza da mediação, se é técnica de autocomposição ou de heterocomposição.

A arbitragem é forma de heterocomposição, em que um terceiro, não investido de poder jurisdicional, decide o conflito pelas partes. Para Amador Paes de Almeida (1998, p. 342), a arbitragem voluntária surge quando as partes, por consenso, livremente escolhem um árbitro, que dirime o conflito e fixa as soluções que entender cabíveis. 
No Brasil, a arbitragem é facultativa e ainda não faz parte dos costumes do sistema de relações de trabalho como ocorre em outros países.

O sistema jurisdicional é meio de heterocomposição dos conflitos trabalhistas e é função do Estado, exercido pela Justiça do Trabalho. A jurisdição deve ser ampla e geral, pois não se pode negar a solução dos conflitos pelo Poder Judiciário.

No caso dos conflitos coletivos do trabalho, é imprescindível que tenha sido esgotada a negociação coletiva para a propositura da ação coletiva, como exigência constitucional com vistas a incentivar a autocomposição dos conflitos coletivos.

Os conflitos coletivos submetidos ao Judiciário são chamados de dissídios coletivos, que são de competência originária, em regra, dos Tribunais Regionais do Trabalho.

De acordo com a definição de Sergio Pinto Martins (2005, p. 600), dissídio coletivo é "o processo que vai dirimir os conflitos coletivos do trabalho, por meio de pronunciamento do Poder Judiciário, criando ou modificando condições de trabalho para certa categoria ou interpretando determinada norma jurídica".

Apesar de ser comumente definido como processo, o dissídio deve ser entendido como o próprio conflito instaurado judicialmente. Assim, o dissídio dá origem à ação.

Eduardo Gabriel Saad (1994, p. 427) alerta que "difundiu-se o uso da expressão 'dissídio coletivo' para designar a ação coletiva. Esta tem como finalidade a solução do dissídio coletivo [...]".

Ísis de Almeida (1998, p. 365) ressalta, ainda, que se deve diferenciar a ação coletiva da ação individual plúrima. Ação coletiva é originada em dissídio coletivo, em que são discutidos interesses abstratos de uma categoria. Na ação individual plúrima, são debatidos interesses concretos individuais de mais de um trabalhador, formando um litisconsórcio ativo.

Os dissídios coletivos também recebem uma classificação doutrinária conforme o conflito coletivo em questão. Roberto Barretto Prado (1971, p. 741) classifica em dissídios de direito, quando têm "por objeto a interpretação de cláusula de convênio coletivo de trabalho ou de dispositivo legal de natureza trabalhista" e dissídios de interesse quando têm "por finalidade criar novas normas". 
Os dissídios de direito são também conhecidos por dissídios jurídicos e os dissídios de interesses por dissídios econômicos, visto que versam, respectivamente, sobre os conflitos coletivos jurídicos e econômicos.

Amauri Mascaro Nascimento (2002, p. 645) e Wagner D. Giglio (2002, p. 384) preferem classificá-los em processos coletivos constitutivos, quando criam ou constituem novas normas, e declaratórios, quando se limitam a interpretar norma coletiva convencional ou legal.

Eduardo Gabriel Saad (1994, p. 441) explica que:

No dissídio coletivo, o interesse é abstrato e as partes envolvidas no litígio não são limitadas; a respectiva sentença produz efeitos que atingem aos que, no momento, sejam empregados das empresas, como também os que vierem a ser admitidos depois, mas durante o prazo de vigência da mesma sentença.

Dessa forma, a sentença em ações coletivas possui características específicas. No dissídio coletivo jurídico, a sentença tem natureza declaratória da existência ou inexistência de relação jurídica. No dissídio coletivo de natureza econômica, sua natureza é constitutiva, visto que cria novas regras para a categoria. (MARTINS, 2005, p. 600).

Ísis de Almeida (1998, p. 293) explica que:

a ação coletiva constitutiva [...] contém elemento 'declarativo', mas nunca poderia assumir a condição de condenatória, pois não se extrai, da sentença pretendida, um título executório. A decisão, antes de tudo, é 'normativa', abstrata, referindo-se a uma categoria, sem identificação pessoal dos destinatários.

Por ser uma decisão que institui normas, a sentença que põe fim a um processo de dissídio coletivo econômico chama-se sentença normativa. Francesco Carnelutti trazia que essa sentença tem "alma de lei em corpo de sentença" (CARNELUTTI apud VIDAL NETO, 1983, p. 126). Conforme Renato Fleischmann (1995, p. 60), a sentença normativa "tem natureza híbrida, com característica de ato jurisdicional, assim como de ato legislativo".

A sentença normativa é a manifestação do poder normativo concedido ao poder judiciário trabalhista. Assim, o poder normativo surge nos dissídios de natureza econômica, quando os Tribunais do Trabalho têm a possibilidade de estabelecer normas e condições de trabalho, oponíveis erga omnes à categoria profissional e à categoria econômica ou empresa envolvida no litígio. 


\subsection{Da importância da participação do estado na solução dos conflitos coletivos}

A função normativa surgiu inicialmente na Itália, sob o regime fascista, numa época em que as greves e os lockouts eram vedados e punidos, confiando-se à magistratura do trabalho a incumbência de dirimir os dissídios coletivos que surgiam (BATALHA, 1995, p. 398).

A Carta del Lavoro, de 1927, estabelecia, em seu artigo $V^{3}$, a competência da magistratura do trabalho para regular as controvérsias, tanto com relação aos conflitos jurídicos, como na determinação de novas condições de trabalho.

No Brasil, os conflitos econômicos sempre foram, via de regra, solucionados pela via jurisdicional. O poder normativo nasceu junto com a Justiça do Trabalho, ainda em sua fase administrativa (GARCIA, 2002, p. 122).

O Decreto 21.396 , de 12 de maio de 1932, foi o primeiro dispositivo legal a prever uma intervenção estatal na solução dos conflitos trabalhistas, instituindo as Comissões Mistas de Conciliação e a Arbitragem, que podia ser realizada pelo Ministério do Trabalho.

Desde a Constituição de 1934, é conferida aos Tribunais do Trabalho a possibilidade de proferirem, nos dissídios coletivos, sentenças normativas, fixando normas e condições de trabalho (BATALHA, 1995, p. 406). A Constituição de 1937 consagrou o poder normativo e somente na Constituição de 1946 foram fixados limites ao exercício do poder normativo. Todas as Constituições posteriores também trouxeram previsão expressa da função normativa na Justiça do Trabalho.

Wilson Ramos Filho (1999, p. 216) conceitua poder normativo como "a possibilidade que o ordenamento jurídico nacional atribui aos Tribunais do Trabalho de criar normas coletivas aplicáveis erga omnes a todos os integrantes de determinada categoria profissional".

Para Amador Paes de Almeida (2005, p. 432), poder normativo é "a faculdade atribuída à Justiça do Trabalho de estabelecer, nos dissídios coletivos de natureza econômica, normas e condições de trabalho".

3 Carta del lavoro - "Art. V. La magistratura del lavoro è l'organo con cui lo Stato interviene a regolare le controversie del lavoro, sia che vertano sull' oservanza dei patti e delle altre norme esistenti, sia che vertano sulla determinazione di nuove condizioni del lavoro" (BATALHA, 1995, p. 398). 
A atribuição de função normativa ao Judiciário, como instrumento de composição dos conflitos coletivos, está presente apenas na Justiça do Trabalho. Essa solução jurisdicional dos conflitos coletivos de trabalho existente no direito brasileiro, contudo, sempre foi objeto de muitas discussões entre os doutrinadores.

Orlando Teixeira da Costa $(1983$, p. 141) explica que essas fontes normativas, à margem do Poder Legislativo, são admitidas "com a finalidade de garantir um perfeito entrosamento dos ritmos de vida do trabalho e da vida jurídica da sociedade".

Segundo Ives Gandra Martins Filho (2003, p. 12), a função normativa na Justiça do Trabalho é explicada pelo "dinamismo das relações econômico-trabalhistas". Como há uma rápida evolução e alteração nas condições da prestação de serviços, a regulamentação jurídica também deve ser rápida.

O mesmo autor, no entanto, faz uma análise crítica da função normativa, ao considerar que "a intervenção estatal na solução dos conflitos coletivos, tal como praticada no Brasil através do Poder Normativo da Justiça do Trabalho, tem apresentado uma série de inconvenientes, que colocam em xeque a própria eficácia e oportunidade do sistema" (MARTINS FILHO, 2003, p. 35).

Como desvantagens, o autor cita o enfraquecimento da liberdade negocial, o desconhecimento real das condições do setor, a demora nas decisões, a generalização das condições de trabalho, a incompatibilidade com a democracia pluralista e representativa e o maior índice de descumprimento da norma coletiva. Por outro lado, elenca duas justificativas para a manutenção do Poder Normativo da Justiça do trabalho: a ausência de um sindicalismo forte no Brasil e a necessidade social de superar o impasse na ausência de autocomposição (MARTINS FILHO, 2003, p. 35-37).

Na visão de Pedro Carlos Sampaio Garcia (2002, p. 125), a função normativa “inibe a negociação coletiva entre os atores sociais, que se acomodam com a intervenção judicial e não procuram a solução autônoma para os conflitos laborais econômicos".

Carlos Henrique Zangrando (1994, p. 23), por sua vez, defende que a função normativa é necessária à Justiça do Trabalho:

[...] temos que o Poder Normativo é uma necessidade prática, uma vez que permite ao órgão judiciário adequar suas decisões à capacidade e ao desenvolvimento econômico das classes envolvidas no dissídio. Assim, a Justiça do Trabalho tem 
poderes para 'acomodar' a rigidez da legislação trabalhista nacional aos desníveis existentes entre as diferentes áreas econômicas e geopolíticas da Nação [...].

Bento Herculano Duarte Neto (1994, p. 23) também defende a intervenção estatal na solução dos conflitos, ao expor que:

\begin{abstract}
é para proteger os trabalhadores desamparados, sem uma retaguarda sindical eficaz, que se impera a necessidade de um determinado intervencionismo estatal, em relação inversamente proporcional à força dos obreiros enquanto componentes de uma categoria profissional respectiva. Quanto mais forte a categoria, menor deve ser o intervencionismo; quanto menos forte, maior deve ser a ação do Estado.
\end{abstract}

O Brasil ainda não possui um sindicalismo forte, capaz de efetivamente pressionar as empresas à negociação coletiva. Torna-se imperativo, por essa razão, que o Estado possa intervir sempre que acionado. Além disso, ainda que as categorias busquem uma autocomposição, em muitas questões a negociação coletiva pode restar frustrada, e o Estado é o único meio disponível para a pacificação das relações de trabalho.

O debate sobre a necessidade da função normativa na Justiça do Trabalho tornouse ainda mais acirrado com as inovações trazidas pela Emenda Constitucional 45 de 2004, que alguns entendem como tendo colocado fim ao poder normativo.

\title{
3 Das alterações promovidas pela Emenda Constitucional 45/04 na solução dos dissídios coletivos do trabalho
}

\subsection{Inovações para a instauração do dissídio coletivo}

A Emenda Constitucional no 45, de 8 de dezembro de 2004, trouxe mudanças significativas no âmbito dos dissídios coletivos. A nova redação imposta ao artigo 114 , $\S 2^{\circ}$, da Constituição Federal estabelece que:

$\S 2^{\circ}$ Recusando-se qualquer das partes à negociação coletiva ou à arbitragem, é facultado às mesmas, de comum acordo, ajuizar dissídio coletivo de natureza econômica, podendo a Justiça do Trabalho decidir o conflito, respeitadas as disposições mínimas legais de proteção ao trabalho, bem como as convencionadas anteriormente. (grifo nosso) 
A alteração que vem suscitando maiores discussões é o acréscimo da expressão "comum acordo" ao parágrafo segundo do artigo 114 do texto constitucional. O debate gira em torno do consenso mútuo como pressuposto para o ajuizamento do dissídio coletivo.

Muitos doutrinadores vêm se inclinando no sentido de que os dissídios coletivos de natureza econômica só podem, agora, ser propostos com a anuência da parte suscitada.

Ives Gandra Martins Filho (2005, p. 198) entende que, "com a promulgação da Emenda Constitucional n. 45/04, o Poder Normativo da Justiça do Trabalho somente pode ser exercido no caso de ambas as partes postularem a intervenção da Justiça Laboral para a composição do conflito".

Cássio Mesquita Barros (2005, p. 287) igualmente atesta que "não havendo esse consenso, permanece o conflito aberto".

O magistrado Alexandre Nery de Oliveira (2005), que foi membro da Comissão de Reforma do Judiciário da Associação dos Magistrados Brasileiros, considera que o poder normativo é agora admitido apenas "em caráter restrito, nos limites apresentados pelas partes, em petição conjunta, respeitadas as condições mínimas de proteção ao trabalho descritas em norma legal ou em normas coletivas anteriores".

Alguns autores entendem que a intenção do legislador, ao incluir a exigência do comum acordo para o aforamento dos dissídios de natureza econômica, foi estimular as negociações coletivas.

A magistrada Andréa Presas Rocha (2006) manifestou sua opinião:

Nos parece que o Legislador Reformador teve em mente a salutar valorização da composição dos conflitos coletivos diretamente pelas partes envolvidas, uma vez que a alteração do texto constitucional privilegia a negociação direta entre os interlocutores sociais, pondo de lado a intervenção estatal, antes aviada pelo poder normativo atribuído à Justiça do Trabalho.

Com o mesmo ponto de vista, Júlio Bernardo do Carmo (2005, p. 595) explica:

A intenção do legislador constituinte foi acabar radicalmente com o vezo das partes se mostrarem pouco dispostas à negociação coletiva preferindo comodamente aninhar-se no seio protetor do paternalismo estatal, expediente que sem dúvida só contribui para enfraquecer ainda mais os sindicatos dos trabalhadores. 
Há muitos anos, alguns autores vêm defendendo uma menor intervenção do Estado e maior incentivo às negociações coletivas. Eduardo Gabriel Saad (1994, p. 472), manifestou sua opinião no sentido de que se deve

abrir campo às negociações diretas entre patrões e empregados para discutir fórmulas que superem suas divergências. E só eles - e não os juízes - sabem ao certo até que ponto a empresa pode fazer concessões sem ameaçar sua sobrevivência. Só assim os empregados ficam em condições de evitar, em muitos casos, o mal maior representados pelo desemprego.

O mesmo autor alegava ser forte a presença do Estado brasileiro nas relações de trabalho, sendo necessário fazê-lo recuar, para que a legislação trabalhista possa ser modernizada.

Nesse debate, Bento Herculano Duarte Neto (1994, p. 58) explica que, embora acredite que a negociação coletiva seja o ponto central da dinâmica do direito do trabalho, "faz-se mister que primeiro haja o fortalecimento da estrutura sindical do país". Segundo o autor, a necessidade da intervenção estatal para a regulamentação das relações trabalhistas manifesta-se já a partir do caráter tutelar do direito do trabalho.

Sabe-se que nem sempre é viável a negociação coletiva e, por conseguinte, pode ser muito difícil a proposição do dissídio coletivo em conjunto.

Júlio Bernardo do Carmo (2005, p. 597), por essa razão, tem entendimento um pouco diverso com relação às alterações promovidas pela Emenda Constitucional no 45, admitindo ser possível, em casos específicos, o suprimento judicial do consenso da parte contrária

se o sindicato dos trabalhadores for inexpressivo, tíbio, sem poder de barganha contra o patronato e sem meios de exercer com sucesso o direito de greve, a recusa de consentimento da categoria econômica para o ajuizamento conjunto do dissídio coletivo de natureza econômica pode sim caracterizar a recusa abusiva, injurídica ou de extrema má-fé que obsta potestativamente o exercício do direito de ação coletiva por parte do operariado. Neste contexto parece-me que a parte prejudicada poderá sim, de imediato, ajuizar o dissídio coletivo de natureza econômica e nele requerer de forma incidental o suprimento judicial da recusa da categoria econômica contraposta. (grifo nosso) 
De acordo com esse entendimento, o Tribunal poderia outorgar o suprimento judicial e permitir a tramitação normal do dissídio nos casos em que identificar má-fé, abuso de direito ou ilicitude por parte da categoria econômica que denegou o consentimento.

Em razão da grande dificuldade de se concretizar a propositura do dissídio coletivo em consenso, outra parte da doutrina não concorda com a interpretação literal da nova redação constitucional.

Arnaldo Süssekind (2005, p. 1031) entende que é possível a instauração do dissídio coletivo, ainda que por apenas uma das partes, pois "se assim não for e configurado o litígio coletivo de interesse, ter-se-á de concluir que as mencionadas regras resultantes da EC n. 45 impõem à categoria profissional o apelo à greve".

Amauri Mascaro Nascimento (2006, p. 654) também defende que ainda é possível a instauração unilateral, realizando uma interpretação lógico-sistemática, como único meio de se conduzir o intérprete ao verdadeiro sentido do texto.

Assim, juntamente com a nova exigência para a propositura do dissídio coletivo de natureza econômica, nasceu um grande debate, que envolve questões processuais, função normativa, forma de jurisdição alternativa, meios de interpretação do dispositivo e, especialmente, a discussão sobre a inconstitucionalidade do novo pressuposto.

\subsubsection{Da questão processual}

A doutrina não conseguiu chegar a um consenso sobre qual será a natureza jurídica do "comum acordo" para a propositura do dissídio coletivo e nem mesmo como será o processamento do dissídio econômico na prática jurídica.

Discute-se, se a necessidade de consentimento é uma condição da ação ou um pressuposto processual ou de procedibilidade para a instauração do dissídio.

Conforme esclarece Humberto Theodoro Júnior (2003, p. 55), os pressupostos processuais são requisitos para a validade e eficácia da relação processual, para a constituição e o desenvolvimento regular do processo. Incumbe ao autor atingir esses pressupostos e também atender às condições da ação, sem os quais o juiz se recusará a apreciar o pedido da causa. Se não forem atendidos os pressupostos processuais, a relação processual nem mesmo se estabelece ou não se desenvolve validamente, já as condições da 
ação são requisitos a serem observados depois de estabelecida regularmente a relação processual, para que o juiz possa solucionar o mérito.

O reconhecimento da ausência dos pressupostos processuais ou da inexistência de condição da ação (carência de ação) leva à extinção do processo sem resolução do mérito (artigo 267, IV e VI do Código de Processo Civil).

Para Julio Bernardo do Carmo (2005, p. 594), a emenda constitucional

criou iniludivelmente um pressuposto de procedibilidade do ajuizamento do dissídio coletivo que antes não existia, sendo que sem o atendimento desse requisito o dissídio coletivo de natureza econômica deve sim ser de pronto indeferido pelo Tribunal Competente [...]. (grifo nosso)

Andréa Presas Rocha (2006) também afirma “que o 'comum acordo' é pressuposto processual de constituição e desenvolvimento do processo [...], sem o qual não se estabelece a relação jurídica inerente ao dissídio".

O sub-procurador-geral do trabalho Edson Braz da Silva (2005, p. 1038) defende que o "comum acordo" ostenta a natureza de condição específica da ação e não pressuposto processual, por entender que não se deve exigir excessiva formalidade processual na propositura do dissídio, a fim de não se perder sua finalidade que é o restabelecimento da paz social.

Com esse entendimento, não há exigência de petição em conjunto ou em concordância prévia e expressa da parte contrária e a aquiescência do suscitado valeria mesmo quando manifestada tacitamente no curso do processo. Se o suscitado não concordar, deverá manifestar expressa oposição ao ajuizamento unilateral do dissídio na primeira oportunidade, já no início da audiência de conciliação. Conforme Edson Braz da Silva (2005, p. 1042), se participar normalmente da tentativa de conciliação, terá tacitamente suprido a exigência legal do comum acordo.

Já houve manifestações do Tribunal Superior do Trabalho no sentido de que a expressão comum acordo não significa, necessariamente, petição conjunta e tampouco precisa ser prévio, e pode se verificar de modo expresso ou tácito.

Para Amauri Mascaro Nascimento (2006, p. 655), não foi criada uma condição da ação e nem mesmo um pressuposto processual. Como o requisito exige a concordância do réu (comum acordo), será o réu quem irá decidir sobre a possibilidade ou não do processo 
contra si. Não há, assim, nova condição da ação ou pressuposto processual a ser cumprido pelo autor, mas uma inversão do direito de ação, pois transfere o poder de agir do autor para o réu.

\subsubsection{Normatividade ou forma de jurisdição alternativa?}

Os dissídios coletivos de natureza econômica permitem o exercício de normatividade pelo Judiciário, que cria, modifica ou extingue normas e condições de trabalho.

Em razão da necessidade da propositura do dissídio em conjunto, a doutrina começou a entender que os dissídios econômicos não serão mais uma manifestação do poder normativo, mas terão natureza de arbitragem, visto que as partes procuram um terceiro - Justiça do Trabalho - para solucionar seu conflito.

Octávio Bueno Magano (2005, p. 290) entende que, pelo novo texto constitucional, o dissídio coletivo de natureza econômica passou a "tratar-se, na verdade, de arbitragem pública".

Alexandre Nery de Oliveira (2005) considera que a Emenda 45/04

atribuiu inequívoca atuação arbitral (ainda que anomalamente estatal) pelos Tribunais do Trabalho, sempre que provocados pelas partes interessadas, que entregam à jurisdição estatal a decisão sobre o conflito instaurado, nos termos que apresentam, para decisão, inclusive sob juízo de eqüidade.

O autor explica que o novo texto constitucional "deixou às partes a decisão sobre a confiabilidade da decisão acerca do conflito aos Tribunais do Trabalho, que funcionam assim como órgãos de arbitragem, embora providos de toda a força inerente à atuação como órgão de Poder do Estado" (OLIVEIRA, 2005).

No mesmo sentido, Andréa Presas Rocha (2006) explica que "somente haverá dissídio, e, consequentemente, sentença normativa, se os litigantes assim o desejarem, ou seja, se as partes, voluntariamente, se submeterem à atuação da Justiça do Trabalho, cuja atividade correspondente, por tal razão, passa a assumir um caráter de arbitragem pública". 
Edson Braz da Silva (2005, p. 1039) acredita que há uma nova concepção para o poder normativo, que fica agora reservado às partes como uma espécie de arbitragem judicial.

\subsection{Da inconstitucionalidade das alterações trazidas pela EC 45/04}

O consenso para a propositura da ação, por vezes, torna-se impraticável. Se as partes envolvem-se em animosidade suficiente para impedir a concretização das negociações coletivas e da arbitragem, pode isso também impedir o comum acordo para a propositura do dissídio coletivo.

Dessa forma, independentemente de ser considerado pressuposto processual ou condição da ação, e de ser manifestação do poder normativo ou arbitragem pública, a impossibilidade de um acordo para a apresentação do conflito ao judiciário pode levar a uma perpetuação da situação de conflito coletivo e gerar graves repercussões sociais.

Por essa razão, questiona-se a validade da exigência de "comum acordo" para a instauração dos dissídios econômicos frente ao Princípio da Inafastabilidade da Prestação Jurisdicional, com o argumento de que o novo requisito fere o direito de ação, sendo, por conseguinte, inconstitucional.

Percebe-se, assim, que se estaria afastando o conflito de uma tutela jurisdicional, por haver uma exigência na maior parte das vezes impossível de se satisfazer. Não se pode exigir do autor um requisito impraticável, sob pena de se estar cerceando seu direito de agir.

A propositura da ação em comum acordo acaba por transferir o direito de ação ao réu, pois o autor só pode ter sua ação tramitando se o réu assim o quiser. Não existe no ordenamento jurídico qualquer ação que tenha como pressuposto que a parte contrária deva concordar que a ação seja movida contra ela (NASCIMENTO, 2006, p. 656). Estaria surgindo no ordenamento uma figura atípica, uma ação que exige concordância do réu para que possa ser recebida ou julgada.

A doutrina, então, traz inúmeros argumentos para defender ser ainda possível a propositura do dissídio por somente uma das partes. O primeiro deles é em relação ao modo de interpretação do novo dispositivo constitucional. 
A interpretação da Constituição não pode levar a conclusões absurdas ou em contradição com o Direito. Amauri Mascaro Nascimento (2006, p. 654) explica que o jurista deve apoiar-se na interpretação lógico-sistemática.

O ex-ministro Carlos Maximiliano (2003) trazia que "o Direito interpreta-se inteligentemente; a exegese não pode conduzir a um absurdo, nem chegar a conclusão impossível". Cabe ao hermeneuta sempre se preocupar com as conseqüências de suas interpretações.

Defendendo as idéias de Carlos Maximiliano, Arnaldo Süssekind (2005, p. 1031) entende que o inalienável direito de acesso ao Judiciário justifica a instauração unilateral do dissídio coletivo, para que não se conclua o absurdo de que a Constituição objetiva estimular a deflagração de greve. Deve, assim, ser possível o ajuizamento por uma das partes, para que não seja imposto o apelo à greve aos trabalhadores, seja para forçar o empregador a consentir com o ajuizamento do dissídio, seja para, sendo atividade essencial, levar o Ministério Público a instaurar o dissídio.

Süssekind (2005, p. 1031) explica em outro artigo publicado sobre o tema que "seria desarrazoado que a Carta Magna se limitasse a proteger o interesse público no suporte fático da greve e deixasse sem solução a lesão ao interesse privado, muitas vezes com repercussão na comunidade, ferindo, portanto, interesses públicos".

Wilma de Araújo Vaz da Silva (2005, p. 1036) também alerta que a condição de comum acordo inviabiliza o dissídio econômico pela via pacífica e tem como efeito colateral indissociável a instigação para a solução mediante greve, como instrumento de pressão cuja deflagração a lei não sujeita à anuência do poder econômico. Segundo a magistrada, só esse argumento já seria suficiente para ser rejeitada a exegese da obrigatoriedade do comum acordo.

Ademais das formas de interpretação do dispositivo, uma Emenda Constitucional, fruto do Poder Reformador, não pode realizar alterações que violem cláusulas pétreas, como o direito fundamental previsto no artigo 5으, inciso XXXV, do texto constitucional, de que a lei não excluirá da apreciação do Poder Judiciário lesão ou ameaça a direito.

Conforme prevê a Constituição, nenhuma limitação impeditiva de ingresso em juízo pode ser imposta. A instauração mediante comum acordo não poderia, por essa razão, ser a única possibilidade de solução pacífica do conflito, excludente do constitucional direito de 
ação que é "personalíssimo e insuscetível de ser compartilhado pela parte contrária" (SILVA, 2005, p. 1035).

A defesa dos direitos coletivos ou individuais da categoria, inclusive em questões judiciais ou administrativas, cabe aos sindicatos, conforme prevê o artigo 8o da Constituição Federal. Sendo o dissídio coletivo o meio por excelência destinado à defesa dos direitos e interesses coletivos e sendo vedado o afastamento da tutela jurisdicional, Arnaldo Süssekind (2005, p. 1032) conclui ser esta uma outra razão para se admitir a instauração do dissídio por apenas umas das partes. Com suas palavras:

[...] o artigo 5ㅇ, XXXV, da Constituição, como cláusula pétrea, assegura o direito da entidade sindical, uma vez malograda a negociação coletiva, de ajuizar o dissídio coletivo, ainda que sem a concordância da entidade patronal - garantia que se harmoniza com o prescrito no art. $8^{\circ}$, III, do ordenamento constitucional .

José Carlos da Silva Arouca (2005) também entende ser possível a instauração de dissídio unilateralmente, "porque foi mantido o mais que o poder normativo, ou seja, o inciso III do artigo 8 o da Constituição, quer dizer, a defesa pelo sindicato de interesses - e não de direitos - coletivos".

Wilma Vaz da Silva (2005, p. 1034) entende que "não se pode extrair [...] uma interpretação que atente contra o direito de ação e consagre a inserção, nos respectivos requisitos de admissibilidade, de alguma das modalidades de condição obstaculizadas pelos princípios contidos nos arts. 122, 123 e 124 do vigente Código Civil”.

Conforme suas explicações, o negócio jurídico resulta inexistente quando sujeito a condições impossíveis, sendo defesas as condições potestativas, que "privarem de todo efeito o negócio jurídico ou o sujeitarem ao puro arbítrio de uma das partes" (SILVA, 2005, p. 1034). Logo, a autora conclui que "há de ser tida como inexistente a condição (da ação) que obriga ao impossível" (SILVA, 2005, p. 1034), como o "utópico assentimento explícito do poder econômico" (SILVA, 2005, p. 1035). Alega ainda que a "distribuição, entre as partes litigantes, de um requisito de admissibilidade que, se não satisfeito, prejudicará apenas uma delas, e precisamente aquela que fica submetida ao exclusivo arbítrio da outra, tipifica a condição potestativa" (SILVA, 2005, p. 1035).

Seguindo esse entendimento, a exigência de comum acordo é uma condição impossível ou potestativa. Se o comum acordo fosse uma nova condição da ação coletiva, 
seu descumprimento levaria a uma extinção do dissídio sem julgamento do mérito. Esse resultado favorável ao empregador faria com que ele nunca optasse pela autocomposição ou arbitragem, frustrando como conseqüência também o comum acordo.

Amauri Mascaro Nascimento (2006, p. 649) demonstra a inconstitucionalidade material de norma constitucional, quando esta viola postulados fundamentais do ordenamento jurídico. Nesse caso, a modificação introduzida pela Emenda contraria princípio fundamental da Constituição, que é o direito público subjetivo de ação.

O artigo 170 da Constituição Federal traz que a ordem econômica é fundada na valorização do trabalho humano, cabendo, dessa forma, ao Estado intervir para sua proteção, seja colaborando para o fortalecimento das entidades sindicais dos trabalhadores, seja por meio da tutela jurisdicional.

Sabendo da grande dificuldade na instauração do dissídio por mútuo consentimento, muitos Tribunais vêm aceitando os dissídios suscitados unilateralmente pelos sindicatos, privilegiando o acesso ao Judiciário e protegendo os interesses dos trabalhadores que acabariam lesados.

Uma decisão do Tribunal Regional do Trabalho da 3a região, com o relator Paulo Roberto Sifuentes Costa, traz que exigir a propositura em comum acordo retiraria da Justiça do Trabalho o poder de julgar o dissídio coletivo, o que levaria ao total descumprimento da Constituição, pois os dissídios visam realizar um julgamento eqüitativo, buscando compatibilizar os valores sociais do trabalho e da livre iniciativa, que são fundamentos da República, previstos no artigo 10 do texto constitucional.

Várias ações diretas de inconstitucionalidade tramitam no Supremo Tribunal Federal, todas sob a relatoria do Ministro Cezar Peluso, questionando a validade do termo "comum acordo".

A Procuradoria-Geral da República, no entanto, se manifestou pela improcedência das ADIn, alegando, na ADIn 3.432-4/600-DF que

o poder normativo da Justiça do Trabalho, por não ser atividade substancialmente jurisdicional, não está abrangido pelo âmbito normativo do art. $5^{\circ}, \mathrm{XXXV}$, da Constituição da República. Assim sendo, sua restrição pode ser levada a efeito por meio de reforma constitucional, sem que seja violada a cláusula pétrea que estabelece o princípio da inafastabilidade do Poder Judiciário (NASCIMENTO, 2006, p. 648). 
Os autos encontram-se com o Relator, aguardando sua manifestação. Não há ainda o desfecho da situação pelo Supremo Tribunal Federal.

Se efetivamente for exigido o mútuo consentimento para a propositura dos dissídios econômicos, os trabalhadores ficarão afastados da tutela do Estado, surgindo um espaço de insatisfação social em razão da litigiosidade contida.

$\mathrm{Na}$ falta de negociação e na impossibilidade de acesso ao Judiciário, os trabalhadores terão como única alternativa a deflagração de greve, movimento que causa prejuízos sociais e econômicos ao país e não deve jamais ser estimulado. Cabe ao Estado buscar solucionar as situações de conflito com justiça, tendo como escopo a pacificação social, razão de ser do Judiciário.

\section{Conclusão}

1. Os conflitos coletivos do trabalho possuem características específicas, por haver principalmente uma relação de desigualdade entre as partes envolvidas no conflito, justificando-se a necessidade de tratamento diferenciado por parte do Estado, se comparado com os conflitos em geral.

2. A ordem econômica fundamenta-se na valorização do trabalho humano (artigo 170 da Constituição Federal). A sua proteção justifica a intervenção do Estado das mais variadas formas, inclusive promovendo o fortalecimento das organizações sindicais representantes de trabalhadores e a manifestação do judiciário na solução dos conflitos. A negociação coletiva deve ser estimulada, sem negar o monopólio da administração da justiça por meio da efetiva prestação jurisdicional coletiva.

3. Nos conflitos coletivos de interesse, que envolvem uma categoria de trabalhadores em busca de melhores condições de trabalho, a função normativa exercida pelo Estado é uma forma de evitar a perpetuação de conflitos, pois, ainda que as categorias busquem uma autocomposição, em muitas questões a negociação coletiva pode restar frustrada e o Estado torna-se o único meio disponível para a pacificação das relações de trabalho.

4. A Emenda Constitucional no 45, de 8 dezembro de 2004, traz a necessidade de "comum acordo" para a instauração do dissídio de interesse. Essa alteração deve ser analisada sistematicamente com todo o texto constitucional. Percebe-se, assim, que se 
estaria afastando o conflito de uma tutela jurisdicional, por haver uma exigência na maior parte das vezes impossível de se satisfazer. Não se pode exigir do autor um requisito impraticável, sob pena de se estar cerceando seu direito de agir.

5. Não permitir o ajuizamento por uma das partes equivale a afastar o conflito coletivo da legítima solução por meio do Estado.

6. Afastar os conflitos de interesse da apreciação do Judiciário pode levar a conseqüências muito graves para a sociedade. Poderá haver uma perpetuação da situação de conflito, gerando grande insatisfação aos trabalhadores, e, inevitavelmente, compelir os trabalhadores à deflagração de greve, pois será a única forma disponível para pressionar as empresas à negociação. A tutela estatal é fundamental para a proteção dos interesses dos trabalhadores, tendo papel essencial na pacificação social dos conflitos.

\section{Referências}

ALMEIDA, Amador Paes de. Curso prático de processo do trabalho. 10. ed. rev. atual. ampl. São Paulo: Saraiva, 1998.

ALMEIDA, Amador Paes de. Curso prático de processo do trabalho. 16. ed. São Paulo: Saraiva, 2005.

ALMEIDA, Ísis de. Manual de direito processual do trabalho. 9. ed. atual. ampl. São Paulo: LTr, 1998. v. 1.

AROUCA, José Carlos da Silva. Justiça do Trabalho. Competência para matéria sindical. Revista LTr, Suplemento trabalhista 053, p. 217-221, 2005.

BARROS, Cassio Mesquita. A reforma judiciária da Emenda Constitucional n. 45. Revista LTr, v. 69, n. 03, p. 277-288, mar. 2005.

BATALHA, Wilson de Souza Campos. Tratado de direito judiciário do trabalho. 3. ed. rev. atual. Ampl. São Paulo: LTr, 1995. v. 2.

CARMO, Júlio Bernardo do. Do mútuo consenso como condição de procedibilidade do dissídio coletivo de natureza econômica. Revista LTr, v. 69, n. 05, p. 593-597, maio 2005.

COSTA, Orlando Teixeira da. A intervenção do Poder Judiciário nos conflitos coletivos de trabalho. Revista LTr, v. 47, n. 2, p. 138-142, fev. 1983. 
DUARTE NETO, Bento Herculano. Temas modernos de processo e direito do trabalho. São Paulo: LTr, 1994.

FLEISCHMANN, Renato. Processo do trabalho: orientação básica. São Paulo: LTr, 1995.

GARCIA, Pedro Carlos Sampaio. O sindicato e o processo: a coletivização do processo do trabalho. São Paulo: Saraiva, 2002.

GIGLIO, Wagner D. Direito processual do trabalho. 12. ed. rev. atual. ampl. São Paulo: Saraiva, 2002.

MAGANO, Octávio Bueno. O direito do trabalho e a reforma do judiciário. Revista LTr, v. 69, n. 3, p. 289-290, mar. 2005.

MALTA, Christovão Piragibe Tostes. Prática do processo trabalhista. 30. ed. rev. aum. atual. São Paulo: LTr, 2000.

MARTINS FILHO, Ives Gandra da Silva. Processo coletivo do trabalho. 3. ed. rev. ampl. São Paulo: LTr, 2003.

MARTINS FILHO, Ives Gandra. Manual esquemático de direito e processo do trabalho. 13. ed. São Paulo: Saraiva, 2005.

MARTINS, Sergio Pinto. Direito processual do trabalho. 24. ed. São Paulo: Atlas, 2005.

NASCIMENTO, Amauri Mascaro. A questão do dissídio coletivo "de comum acordo". Revista $L T r$, v. 70, n. 6, p. 647-656, jun. 2006.

NASCIMENTO, Amauri Mascaro. Curso de direito processual do trabalho. 21. ed. atual. São Paulo: Saraiva, 2002.

NASCIMENTO, Amauri Mascaro. Direito sindical. São Paulo: Saraiva, 1989.

OLIVEIRA, Alexandre Nery de. A reforma do Judiciário e a alteração competencial da Justiça do Trabalho. Jus Navigandi, Teresina, v. 9, n. 681, 17 maio 2005. Disponível em: <http://jus2.uol.com.br/doutrina/texto.asp?id=6733>. Acesso em: 28 ago. 2006.

RAMOS FILHO, Wilson. O fim do poder normativo e a arbitragem. São Paulo: LTr, 1999.

RIBEIRO, Fábio Túlio Correia. Processo do trabalho básico: da inicial à sentença. São Paulo: LTr, 1997. 
ROCHA, Andréa Presas. Dissídios coletivos: modificações introduzidas pela Emenda Constitucional no 45/2004. Jus Navigandi, Teresina, v. 10, n. 996, 24 mar. 2006. Disponível em: <http://jus2.uol.com.br/doutrina/texto.asp?id=8147>. Acesso em: 30 ago. 2006.

RUSSOMANO, Mozart Victor. Direito do trabalho \& direito processual do trabalho: novos rumos. 2. ed. Curitiba: Juruá, 2006.

SAAD, Eduardo Gabriel. Direito processual do trabalho. São Paulo: LTr, 1994.

SILVA, Edson Braz da Silva. Aspectos processuais e materiais do dissídio coletivo frente à Emenda Constitucional n. 45/2004. Revista LTr, v. 69, n. 9, p. 1038-1047, set. 2005.

SILVA, Wilma Nogueira de Araújo Vaz da Silva. Sobre a exigência de comum acordo como condição da ação de dissídios coletivos. Revista LTr, v. 69, n. 9, p. 1033-1037, set. 2005.

SÜSSEKIND, Arnaldo. Do ajuizamento dos dissídios coletivos. Revista LTr, v. 69, n. 9, p. 10311032, set. 2005.

THEODORO JÚNIOR, Humberto. Curso de direito processual civil. 39. Ed. Rio de Janeiro: Forense, 2003. v. 1.

VIDAL NETO, Pedro. Do poder normativo da Justiça do Trabalho. São Paulo: LTr, 1983.

ZANGRANDO, Carlos Henrique da Silva. Resumo do direito processual do trabalho. Rio de Janeiro: Edições Trabalhistas, 1994. 
